\title{
artículos
}

\section{Regalos artísticos en Roma. A propósito de la santificación de Toribio de Mogroviejo}

\author{
Fernando Quiles García \\ Universidad Pablo de Olavide (Sevilla)
}

\section{RESUMEN}

Este artículo estudia la iconografía, contexto histórico-social e impresionante promoción artística acometida por los impulsores de la canonización del primer santo americano Santo Toribio de Mogrovejo, quienes prodigaron un generoso agradecimiento a los personajes más relevantes de la corte papal y la Roma del momento por su contribución al exitoso final de la empresa.

PALABRAS CLAVE: Iconografía/ Barroco/ Santos/ Pintura/ Fiesta.

Artistic gifts in Rome. On the occasion for Toribio of Mogroviejo's
sanctification

ABSTRACT

This article studies iconography, historic and social context and artistic promotion charged by impellers of Saint Toribio de Mogrovejo's canonization process, who tributed an generous gratitude to relevant people of Contemporary Rome and Pontifical Court supporters of this Project and its successful end.

KEY WORDS: Iconography/ Baroque/ Saints/ Painting/ Feasts.

La creación del primer santo americano se produjo de acuerdo a los dictados de la iglesia tridentina, en el deseo de universalizar el proceso de evangelización nuevamente emprendido. Santa Rosa de Lima subió a los altares en muy breve tiempo, fruto del esfuerzo aunado de la iglesia limeña, la orden dominica y la corona española. Fue la respuesta directa a una necesidad, la de proporcionar a la población americana sus propias imágenes de devoción y resortes de convicción. El virreinato de Perú obtenía así un estímulo que el mundo novohispano aguardó durante décadas $^{1}$. Y todavía alcanzaría otras beneficiosas concesiones, como la de santo Toribio de Mogrovejo, cuya canonización se produjo ya en el siglo siguiente, como fruto tardío del mismo impulso².

Frente a santa Rosa, manifestación del sentimiento criollo, santo Toribio, representa más la idiosincracia de la iglesia secular, la misma que sustentó en gran medida el peso de creación de nuevos santos ${ }^{3}$. La misma que en el mundo ameri-

\footnotetext{
* QUILES GARCÍA, Fernando: "Regalos artísticos en Roma. A propósito de la santificación de Toribio de Mogroviejo", en Boletín de Arte, n 30-31, Departamento de Historia del Arte, Universidad de Málaga, 20092010, págs. 97-118. Fecha de recepción: Junio de 2009.

1 RUBIAL GARCÍA, A., La santidad controvertida: Hagiografía y conciencia criolla alrededor de los venerables no canonizados de Nueva España, México, FCE, 1999, págs. 64-72.

2 RÍPODAS ARDANAS, D., "El culto a Santo Toribio de Mogrovejo, un capítulo de la presencia de América en España (1679-1810)", /l Congreso Argentino de Americanistas, Buenos Aires, 1998, t. II, págs. 289-318.

3 HAMPE MARTÍNEZ, T., Santidad e identidad criolla: Estudio del proceso de canonización de Santa Rosa, Lima, Centro de Estudios Regionales Andinos "Bartolomé de las Casas", 1998. La bibliografía relativa a santo
} 
cano se midió con la regular en el control de los fieles y el manejo de las parroquias ${ }^{4}$. Fue su estructurador, un obispo-pastor tridentino al modo de san Carlos Borromeo, que al decir de su biógrafo, era necesario, por ser "un varón apostólico que ejecutase cuanto el Concilio ordena, y fuese un maestro de los prelados y del clero y del mundo todo, que enseñase más con obras que con palabras, la lengua fuese la vida, las palabras los hechos ejemplares, los documentos las obras"5. Su trayectoria se acomoda a ese mismo patrón, una vida de sacrificios y renuncias en pro de su feligresía, concluyéndola mientras cumplía con sus atribuciones, en 1606, durante la segunda visita apostólica a la diócesis limeña. Ésta era la vertiente más atractiva de su comportamiento y la elegida para ensalzarlo en su camino a los altares.

La santificación del virtuoso sacerdote sólo fue posible tras un largo proceso que arrancó años después de muerto y culminó en 1729, con el decreto de canonización y su inscripción en el santoral romano. Ello fue posible con el beneplácito del colegio pontificio y la concurrencia de numerosos hombres de iglesia, diplomáticos e intelectuales. La corona jugó un papel protagonista destacando a sus principales funcionarios italianos, sobre todo el embajador ante la Santa Sede, y una serie de agentes que se sucedieron, a veces de manera abrupta, en la administración del negocio, Alonso Torralba, Juan Antonio Díaz de Arce y Domingo Vaccari. La secuencia de los hechos, como recuerda uno de los gestores, Díaz de Arce, empieza el 20 de diciembre de 1678, con la firma del decreto de beatificación, realizada por Inocencio XI, siendo Toribio anotado en el martirologio el 23 de junio de 1680. Al cabo de unos meses, el 19 de abril de 1681, le fue concedido el rezo. A partir de entonces se emprendió el proceso de canonización, que se sustanciaría con celeridad, en relación con otros casos, incluido el de los siervos de Dios que le acompañaron en la subida a los altares. Tal vez el trance más apurado se produjo en la aceptación de los milagros, puesto que de los doce casos presentados a la Sacra Congregación de Ritos, sólo tres fueron asumidos, los que el pontífice tardaría en sancionar por falta de la adecuada calificación6.

En un acto de revitalización de esta práctica religiosa, empujado por un papa que había tenido que enfrentar el problema jansenista y otras disidencias, fueron ocho los canonizados en 1726: los franciscanos Francisco Solano y Giacomo della Marca, los jesuitas Estanislao de Kotska y Luis Gonzaga, el carmelita Juan de la Cruz, el servita Pelegrino de Laziosi y la dominica Inés de Montepulciano. Una equilibrada acción pontificia que había reforzado nuevamente el santoral de las principa-

Toribio es muy abundante, siendo de destacar la obra de RODRíGUEZ VALENCIA, V., Santo Toribio de Mogrovejo, organizador de Sudamérica, Madrid, CSIC, 1957; SÁNCHEZ PRIETO, N., Santo Toribio de Mogrovejo, apóstol de los Andes, Madrid, BAC, 1986; VARGAS UGARTE, R., Santo Toribio, segundo arzobispo de Lima, Lima, Paulinas, 1989.

4 Río ALBA, J. del, La evangelización del Perú en tiempo de Santo Toribio de Mogrovejo, Biblioteca Redemptoris Mater 2, Callao, 2008.

5 Vida, fol. 4v-5r. en HUERGA, Á., "La irradiación de san Carlos Borromeo en España a principios del siglo XVII", Hispania Sacra, 81, 1988, pág. 186. No es casual esta vinculación, pues en la basílica romana de santa Anastasia, comparten espacio ambos santos, como resaltó MÂLE, E., El Arte Religioso de la Contrarreforma. Estudios sobre la iconografía del final del siglo XVI y de los siglos XVII y XVIII, Madrid, 
les órdenes religiosas, además de la de los Siervos de María y de la iglesia secular. Seguía así los pasos de sus antecesores, Gregorio XV y Clemente X, quienes en 1622 y 1671 , respectivamente, crearon varios santos a la vez, todos ellos figuras representativas de sus respectivas comunidades religiosas.

No es cuestión que nos deba ocupar en estas páginas el procedimiento seguido en la elaboración de los expedientes de beatificación y canonización de santo Toribio. Ni conocer el cometido de las distintas autoridades civiles y eclesiásticas para dar término a los mismo, como tampoco escrutar las razones que impulsaron a crear el nuevo santo. Nos interesa ver la manera como se instrumentalizaron las obras de arte creadas expresamente mientras se materializaba el proceso. $Y$ no tanto la creación de una hagiografía acorde con los intereses de los promotores, como la aportación a la política de regalos empleada para doblegar voluntades?.

No son pocos los estudios que han abordado la creación de la hagiografía barroca en este contexto, como respuesta a una necesidad expresiva, ya sea en el momento en que se debate la oportunidad de crear un nuevo santo, como en el tiempo de su divulgación. Sin embargo, apenas se ha tratado la cuestión del uso de la obra de arte como regalo. $Y$, sin embargo, fue una costumbre que, a nivel general, se ha resaltado:

"En el siglo XVII, tanto los Cardenales como los Consultores, recibían con el retrato del nuevo santo el importe de una capa de camelot rojo, de un roquete y una sobrepelliz; los demás oficiales y camareros el de su respectiva librea, y gratificaciones también correspondientes a sus trabajos los abogados consistoriales y los secretarios de breves"8.

En el caso de Toribio existen relaciones muy explícitas de los gastos y, lo que es más interesante, una nómina de individuos a los que se les regaló con cuadros del santo ${ }^{9}$. En la citada relación de beneficiarios de las obras de arte encargadas por los impulsores del proceso, aparecen reflejados los personajes más influyentes de la corte papal y la Roma del momento, de acuerdo con un plan de allanamiento de obstáculos muy estudiado10.

Hasta noventa y ocho nombres figuran en la lista, asociados a las calidades de las obras, ya sea original o copia, de un maestro u otro. La encabezan el pontífi-

Encuentro, 2001, pág. 86.

${ }_{7}$ A[rchivo] G[eneral de] I[ndias]. Patronato, 249, R. 7 (1).

7 Aunque es un tema al que le he dedicado diversos trabajos, que vienen a sumarse a lo que otros especialistas han elaborado, me remito al más reciente por su carácter sintético: "La invención de la forma y la concreción del gesto. La hagiografía creada para la Sevilla barroca", en DE CARLOS, M. C., PEREDA, F., VICENT-CASSY, C. [coords]: Usos y espacios de la imagen religiosa en la Monarquía hispánica del siglo XVII, Casa de Velázquez, Madrid, 2008, págs. 135-149.

8 La cuenta sigue y los postuladores debían hacer cuantiosos desembolsos, lo que restringía su número y, por ende, el de los procesos. Cfr. ANDRÉS, Fr. A., OSB., "Gastos de la canonización de San Raimundo de Peñafort", Hispania Sacra, 3/5, 1950, pág. 164.

9 De soslayo lo he tratado en casos muy cercanos, en especial el trabajo realizado con ARANDA BERNAL, A. M: "El valor de la imagen en el proceso de beatificación y canonización de Sor Francisca Dorotea", 


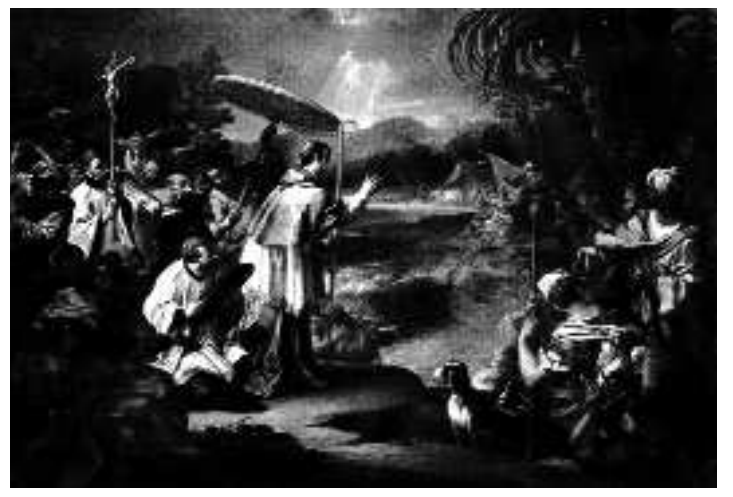

1. Sebastiano Conca, Milagro de San Toribio Vescovo de Lima, 1726. Archivos Vaticanos, $n^{\circ}$ inv. 40836 .

ce y el rey. Al primero le correspondió la mejor pieza de todas, original de Sebastiano Conca, apreciada en 450 escudos; al segundo otra del mismo artífice, pero tasada en 300 escudos. Otra pieza importante, original de Francesco Trevisani, fue entregada a santa Anastasia. De menor cuantía, como evidente demostración de la menor relevancia del personaje, fueron las dos copias de Trevisani hechas para el ponente, el cardenal Albano, y la Iglesia de Lima. Ambas fueron evaluadas en 50 escudos. Y diez menos las copias de Conca y Trevisani, dadas al resto de los relacionados. Entre otros apellidos conocidos, pertenecientes a los consultores y cardenales romanos, se encuentran Barberini, Ottoboni, Gualtieri, Marefoschi, Corradini, Conti, Bentivoglio, Colonna y Orsini. Llama la atención que también la reina de Inglaterra se hizo merecedora de uno de estos cuadros. De menor cuantía aún eran las pinturas, copias de los mismos artistas, las correspondientes a los religiosos, miembros de la curia, participantes en el proceso, el promotor de la fe, el notario de ritos, etc. Algunos de ellos obtuvieron copias de Nicolás Ferri. Por último, hay que consignar tres estandartes encomendados a Pedro León Ghezzi, Plácido Costanzi y Onofre Avelino, los dos primeros para las iglesias de Lima y san Pedro de Roma y el tercero -y más barato- para el colegio de Osuna, en Salamanca. Sólo estas partidas generaron un gasto de 6.086 escudos y 40 bayoques, una cifra abultada que acabaría ocasionado ciertas susceptibilidades. Concretamente el cardenal Bentivoglio expresaría por escrito su opinión acerca de esta desmesurada cifra, en una carta escrita a Francisco Díaz Román el 10 de septiembre de 1727. En un pasaje de la misma diría:

"Toda la suma de quadros, estandartes, y lo demas para dho efecto, importa 6086 exdos y $40 \mathrm{bs}$, los quales se han distribuido en la forma q se prescrive al folio señalado con la letra D. Y hablando en primer lugar de la suma, esta es excesiva en todas sus partes, respecto de q no se hallará causa de canonizazion hecha asta ahora, q haya consumido tanto dinero para tal efecto. Por los otros siete sto canonizados con sto Toribio se han gastado por cada uno 
menos de 2. Exos con q no se comprende como por el solo sto Toribio se a triplicado el dispendio. El dinero juntado $p^{a}$ esta causa fue recogido de limosnas de fieles, y destinado para la gloria del sto la qual en nada se ha augmentado con gastarse de su Patrimonio una summa tan considerable..."11.

La cifra dada de 26.560,41 escudos rebasó con creces la alcanzada por otro proceso paralelo, el de santa Inés de Montepulciano, que se aproximó a los 18.000 escudos ${ }^{12}$

Hubo intentos de recortar gastos, en algún caso yendo contra la costumbre. Félix Cornejo propuso un ahorro en la adquisición de cuadros, cancelando el segundo de los que le correspondía a Domingo María Vaccari, como procurador de la causa: "...Siendo costumbre, y estilo q entonces se dé uno al Proc'r de ella y otro despues de concluida, y decretada la sanctificacion, que es el que presentemente pretende, $y$ se le debe a Bacari'13.

En el balance definitivo de gastos queda patente la contribución de cada uno de los artífices a este conjunto de regalos. Podemos saber, de este modo, que Conca hizo dos originales y 42 copias, por los que cobró, respectivamente 750 y 1.680 escudos; que Trevisani participó con un original y 44 copias, dos de ellas de mayor calidad. Ferri hizo seis copias, sin especificar de quién. Y Ghezzi, Constanzi y Avelino sendos originales ${ }^{14}$.

Fueron obras encargadas a artífices muy representativos en un momento decisivo para la feliz culminación del proceso, en la década precedente al decreto de canonización. En septiembre de 1720 Ghezzi cobra parte del trabajo de pintura y en mayo y noviembre de 1726 lo correspondiente al estandarte o pendón ${ }^{15}$. Trevisani era retribuido a fines de marzo de 1726 por el cuadro de la capilla, en santa Anastasia, y entre los meses entre junio y noviembre, por las copias ${ }^{16}$. Constanzi liquidaba entre abril y noviembre del mismo año. $Y$ en abril y julio, Avelino. Por esos meses Conca percibe una parte de lo estipulado por el cuadro del Papa ${ }^{17}$. A todos ellos hay que unir José Cucciolini, que participó en la realización del estandarte de Constanzi, con la representación de seis armas por ambos lados del mismo18.

Al margen de los cuadros demandados para el regalo, hay que mencionar los acordados para respaldo de las celebraciones organizadas una vez conseguida la canonización, de ahí las banderolas destinadas a las iglesias de Lima y san Pedro de

\footnotetext{
Laboratorio de Arte, 13, 2000, págs. 363-370.

10 AGI, Patronato, 249, R.17 (1).

11 AGI, Patronato, 249, R. 17 (3)

12 Así se lo hicieron saber al cardenal Bentivoglio en carta datada el 7 de enero de 1728. AGI, Patronato, 249, R. 17 (2).

13 Carta del cardenal Bentivoglio a don Francisco Díaz Román, dada el Roma, el 24 de septiembre de 1727. AGI, Patronato, 249, R. 17 (2).

14 Véase la relación en el apéndice documental.

15 "Al Señor Cauallero Pedro Gherzi escs treynta y ocho por los quadrecitos num 19 que hizo y se distribuyeron a los Consultores de la Congregacion por D. Juan Diaz de los quales no hauia sido pagado como se ha reconocido por los pagamentos hechos... 38". AGI, Patronato, 249, R. 17 (1).

16 AGI, Patronato, 249, R. 17 (1), fol. 8.
} 
Roma, así como el colegio de Oviedo de la ciudad de Salamanca19. Otros espacios reservados para el santo fueron la capilla de la iglesia romana de santa Anastasia, y, en la corte española, el altar principal del templo de los carmelitas calzados, perteneciente al Consejo de Indias. En Roma, la canonización fue celebrada también en la iglesia de Santiago de los Españoles. Precisamente en este templo se festejó por todo lo alto el suceso, con exposición, luminarias e incluso música compuesta para la ocasión ${ }^{20}$.

En la preparación de la basílica romana tuvieron una destacada intervención el arquitecto Raimundo Bianchi y el estuquista Anibal Marzoli, que prepararon los muros de la capilla para asiento del cuadro 21.

Por lo que respecta a las fiestas españolas, hay noticias de lo acontecido en Madrid, que celebró la canonización con cargo a los tres mil escudos romanos puestos a disposición del Consejo de Indias, como organizador de la misma. El lugar elegido para los fastos fue el convento del Carmen, donde se levantó un altar presidido por la escultura del nuevo santo. Y los días señalados para ello fueron el 9, 10 y 11 de junio del 28. Un tributo que se prolongaría en el tiempo, con la permanencia de una imagen del santo en la capilla mayor de la iglesia carmelita22. La Gaceta de Madrid se hizo eco, el 15 de junio de 1728, de la ceremonia:

“El Real Consejo de las Indias celebró por tres días, que fueron el Miércoles, Jueves, y Viernes de la semana passada, con singular ostentación, y magnificencia en la Iglesia del Convento del Carmen Calzado de esta Villa, la fiesta de la Canonización de Santo Toribio de Mogrobejo, Arzobispo de Lima; assistiendo el mismo Consejo en forma de Tribunal a todas estas funciones, en las quales dixo la Missa de Pontifical el Obispo de Isauria, predicaron muy eloquentes Oradores, y tuvo excelente Música de vozes, y de instrumentos"23.

El propio cabildo madrileño quiso celebrar al santo cinco años después de canonizado, encargando al licenciado Antonio Tello de Meneses una obra de teatro que con el título El Sol en el Nuevo Mundo y pastor más vigilante, Santo Toribio de Mogrovejo iba a ser representada en la navidad de 173224. Una composición escrita sobre el texto biográfico de Francisco Antonio de Montalvo (Roma, 1683)25.

\footnotetext{
17 AGI, Patronato, 249, R 17 (1), fol. 8.

18 AGI, Patronato, 249, R. 17 (1).

19 RUPÉREZ ALMAJANO, M. N., "La capilla del colegio de Oviedo, templo de la ciencia y la virtud", Archivo Español de Arte, n 300, 2002, págs. 397-405.

20 AGI, Patronato, 249, R. 17 (1)

21 AGI, Patronato, 249, R 17 (1)

22 Resultaba muy interesante la capilla mayor, en donde estaba el sepulcro de Fray Ambrosio Vallejo, Obispo de Popayán y Trujillo de Indias, quien tomó el patronato de la capilla en 1635, pasando tras su muerte al Consejo de Indias.

23 Crónica festiva de dos reinados en la Gaceta de Madrid (1700-1759), TORRIONE, M., ed., Paris, Editions Ophrys, 1998, 148, $\mathrm{n}^{\circ} 24$.

24 RÍPODAS ARDANAZ, D., "Una comedia sobre Santo Toribio de Mogrovejo en el Madrid de Felipe V", en GUERRA, M., HOlguín, O. y GUTIÉRREZ, C., Sobre el Perú: Homenaje a José Agustín de la Puente
} 
2. TREVISANI, Santo Toribio de Mogrovejo, 1726. Iglesia de Santa Anastasia, Roma.

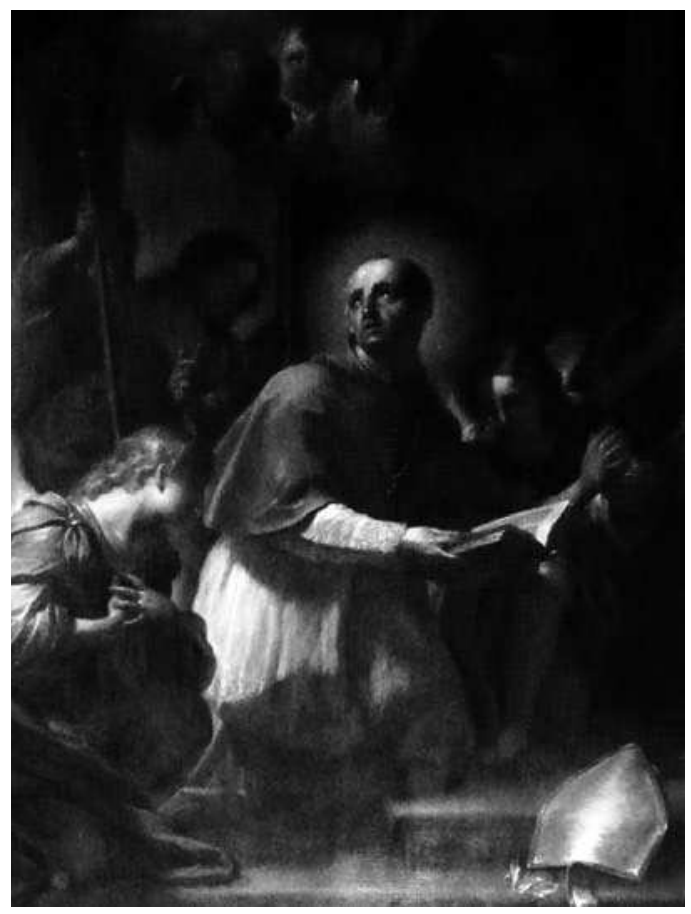

El procedimiento seguido en la configuración de la imagen del santo, requería la participación de un elenco de artistas de reputación. De ahí el interés por contar con los servicios algunos de los más relevantes pintores en activo en la ciudad de Roma en esos momento, especialmente Sebastiano Conca y Francesco Trevisani, ambos protegidos del cardenal Ottavio Ottoboni y del papa Clemente XI. Suyas fueron las matrices, una conservada en los Museos Vaticanos y otra que aún guarda la basílica romana de santa Anastasia26.

El resorte básico de convicción hubo de ser el episodio descrito por Conca, que representa al santo haciendo brotar agua de una roca, para alimentar la seca tierra de la población peruana de Macate. Toribio se encuentra vestido de pontifical y, como un nuevo Moisés, abriendo la vía con su báculo.

La Iglesia quiso recordar su condición de prelado tridentino, comprometido con la iglesia limeña, recién formada. De ahí la importancia de elegir un episodio relacionado con su labor misional. Y ningún mensaje más explícito que el aportado por el cuadro de Conca, que le muestra, además, en uno de los milagros que le hicieron santo. Parecido móvil tuvo la elección del frontispicio de una de sus primeras bio-

Candamón, Lima, PUCP, 2002, II, págs. 1029-1039. 
grafías, la Mirabilis vita (Roma, 1670), donde dos indios se colocan a los pies de la iglesia 27 . También en su papel de prelado es recordado en alguna ocasión, como en la estampa en que consagra a santa Rosa de Lima. Y luego una serie de imágenes que exaltan sus valores cristianos. Interesante es el aguafuerte de Joseph Mulder ("J. Mulder Fecit 1688"), que lleva por título La Estrella de Lima convertida en sol sobre sus tres coronas 28 .

No queda claro si entre los cuadros que se repartieron en Roma existieron retratos. Es muy probable, puesto que se había convertido ya en una costumbre. El retrato es un género básico en el impulso de los procesos de canonización, porque estimulaba la devoción al personaje concreto.

Más allá de las tentativas directas de difundir la imagen del nuevo santo, a una reducida escala, tiempo antes de que en efecto fuera elevado a los altares, habría que considerar la proyección a través de las estampas y con un alcance ilimitado. Apenas canonizado se requirió la asistencia de uno de los más reputados grabadores romanos para abrir una lámina con la efigie del santo. Las cuentas reflejan el coste de la obra, así como el nombre de su autor, Jerónimo Frezza ${ }^{29}$. También aluden a los 200 libros "a la francesa" y los otros 205 "en pergamino con 3 estampas dentro", impresos con el lógico interés por divulgar su biografía 30 . El eco de esta operación llegó a España y seguramente se extendió por América. Y se acrecentó con sucesivas impresiones. Pero esta es otra realidad, cuyo desarrollo requeriría otro estudio.

\footnotetext{
25 Idem, 1033.

26 Como Milagro de santo Toribio, expuesto en la sala XV de la pinacoteca, con el $\mathrm{n}^{\circ}$ de inv. 40836.

27 Mirabilis vita et mirabiliora acta dei Vener. servi Toribij Alfonsi Mogbrobesij, con versión de Anastasio Nicoselli, de 1679 (Compendio della vita del beato Toribio Alfonso Mogrobesio).

28 La portada del libro de Francisco de Echave y Assu, La estrella de Lima..., editado en Amberes por Juan Baptista Verdussen, en 1688. A Mulder ya le conocíamos por el grabado que preparó del original de Lucas Valdés, con la Vera Efiggies de Fernando de Contreras. QUILES, F., "De la concreción", op. cit.
} 


\section{APÉNDICE DOCUMENTAL}

1727-VI-23.

"C

Franco treuisani Pintor por resto de las quarenta copias deue hauer... 204

El mismo treuisani por otra copia mas que ha hecho posteriormente... 24

El mismo treuisani por las telas de los dos quadros grandes a razon de seis escs cada una... 12

Sebastiano Conca por Resto de 42 copias... 380

El dho Conca por resto del quadro que hizo para el Papa.. 150

Egidio Marani por los moldes Moldes que ha hecho para los Agnus del Santo, que quedan en la Guardaropa del Papa... 90

Juan Bautista Lanini por resto de los adornos de los estandartes... 60.20

Onofre Auelino por el Regalo que se le prometió del estandarte que ha hecho para el Colegio de Ouiedo... 20

Joseph Bacile Mercante en Plaza Naona [sic] por resto de los encajes de Oro y Plata... 74

Por el precio de la cera de los Agnus que se han hecho para España y Lima... 70

Lorenzo Curtis carpintero por resto de las cornisas de los quadros, en que se incluye la del Rey nro señor... 21.90

Ant $^{\circ}$ Arno sastre por hauer cosido todos los encages de las estampas por su Hechura y seda... 10

Guillelmo Faiure por la Franja que se puso a la Ymagen del Santo que se dio a la Reyna de Yngalaterra [sic]... 4.50

$\ldots$

Nota de los Accrehedores de dha Causa de Canonizacion que han sido pagados de proprio por Dn Felix Cornejo, quien los deue hauer de la Causa.

Por tantos que ha pagado al Pintor Nicolas Ferri por 2 quadros de a quatro palmos que se hicieron para el Computista y Caxero del Sacro Monte de la Piedad... 20

Por el Decreto de la Missa propria y el oficio de la translacion de la Sta Casa de Loreto, que se concedió para la Diocesis de Lima, y al faquin que lleuó los quadros al Computista y Caxero de el Monte... 1.50

Por tantos pagados a Patricio Tullio tirador de las estampas por finiquito de las estampasde el santo.. 5.78

Por tantos que ha costado un quadro del Santo que se ha dado al Rmo Pe Genl de Sto Domingo... 20

Pagados a Ant ${ }^{\circ}$ Maggi por la Doradura de las Armas del estandarte que hizo Placido Costanzi y tres cornisas... 16.28

Pagados por el Porte hasta Genoua del estandarte para el Colegio de Ouiedo y un cajon de Agnus para el mismo Colegio... 2.80

Pagados a la Aduana por sus derechos de dhos cajones... 1

Pagados por embalar dhos cajones... 4

Pagados por la enquadernacion de quatro libros de la Vida del Sto con Armas doradas que se pidieron para el Gran Duque de Toscana y sras Princesas de Florencia... 2.20

Por las escrituras que se sacaron de la fundacion de la Capilla de Santo Thoribio en la Ygl ${ }^{a}$ de Santa Anastasia... 3.20 
Nota de los Accrehedores de dha causa de canonizacion que todauia no está concertado su precio y credito.

Sebastian Conca por precio del quadro que esta haciendo para S. M. del qual pretende escs 300: y todauia no queda concertado.

Ant $^{\circ}$ Maggi endorador por la cornisa del quadro del Rey la qual no se ha concertado por no estar acabada.

...

Deuense assimismo tomar Medallas del Santo para la Yglesia de Lima, encajonar toda la Ropa, Medallones, estandarte, quadro para el Rey nro Señor, y Consexo de las Yndias, Agnus y demas que se ha de remitir y embalar, y pagar lo que importare su conduccion, que todauia no puede costearse... 45

...

Deuense tambien los gastos menudos que han hecho los officiales de Sebastian Conca y el mismo y las jornadas al official que pintó los Regulos alrededor de los quadros por cuyos gastos se pretenden escs 6 y bs 50 y todauia no está ajustado. $Y$ finalmente se deue la Mancha o aguinaldo a los officiales del estudio del dho Conca... $6^{31}$

$D$

"Nota de los quadros que se han distribuydo para la Canonizacion de S. Thoribio Alphonso Mogrobexo, en conformd de la Lista, que dio el Rmo Pe Genl de Sto Domingo, en que se comprehenden todos los Ssres Cards Consultores y demas Ministros de la Congregon de Ritos, y otras Personas, a quienes se ha considerado ser deuidos, segn las Circumstancs, y por lo que se han interesado en la Causa atendiendo a la preuencion que dho Rmo. Pres General hizo en su Memoria:

${ }^{29}$ AGI, Patronato, 249, R. 17 (1) 


\begin{tabular}{|c|c|c|c|c|c|c|c|c|c|c|c|}
\hline Distribucion & Num ${ }^{\circ}$ & Authores & $\begin{array}{c}\text { Pred } \\
0\end{array}$ & Comisas & Precio & Doradura & $\begin{array}{c}\text { Prec } \\
\text { io }\end{array}$ & & & & \\
\hline Al Papa & $n^{n} 1$ & Origl Conca & 450 & Comisa & 10 & Doradura & 15 & & & & \\
\hline Al Rey nro Sor & $N^{0}-1$ & Origl Conca & 300 & - & 18 & - & - & & & & \\
\hline $\begin{array}{c}\text { A la Reyna de } \\
\text { Yngg" }\end{array}$ & $N^{u} 1$ & Cosiat atho & 40 & - & 5 & - & 8 & & & & \\
\hline Barberin| & $\mathrm{N}^{0} 1$ & Copia tho & 40 & - & 5 & - & 10 & & & & \\
\hline Otthoboni & $N^{4} 1$ & Cupial dthe & 40 & - & 6.70 & - & 10 & & & & \\
\hline Gualtieri & $N^{0} 1$ & Copia dho & 40 & - & 5 & - & 10 & & & & \\
\hline Fabronl & $N^{0} 1$ & Copla the & 40 & - & 5 & - & 10 & & & & \\
\hline Albano Pon" & $N^{n} 1$ & Cupial Truvisarni & 50 & - & 5 & - & 10 & & & & \\
\hline Pico & $\mathrm{N}^{0} 1$ & $\begin{array}{l}\text { Copia de } \\
\text { Concia }\end{array}$ & 10 & - & 5 & - & 10 & & & & \\
\hline Polignach & $\mathrm{N}^{\mathrm{n}} 1$ & Copia dho & 40 & - & 5 & - & 10 & & & & \\
\hline Zondaderi & $\mathrm{N}^{0} 1$ & Copia tho & 40 & - & 5 & - & 10 & & & & \\
\hline Belluga & $\mathrm{N}^{\mathrm{*}} 1$ & Copla the & 40 & - & 5 & - & 10 & & & & \\
\hline Salerno & $\mathrm{N}^{\mathrm{n}} 1$ & Coppia dho & 40 & - & 5 & - & 10 & & & & \\
\hline Cienfuegos & $N^{0} 1$ & Copia dho & 10 & - & 5 & - & 10 & & & & \\
\hline Marefoschl & $\mathrm{N}^{0} 1$ & Conp. Conca & 40 & Comisa & 5 & Doracura & 10 & & & & \\
\hline Pipia & $N^{n} 1$ & Cop dho & 40 & - & 5 & - & 10 & & & & \\
\hline Pamphi西o & $\mathrm{N}^{0} 1$ & Cop dho & 10 & - & 5 & - & 10 & & & & \\
\hline Ymperiall & $\mathrm{N}^{\mathrm{u}} 1$ & Cop dho & 40 & - & 5 & 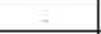 & 10 & & & & \\
\hline Origo & $\mathrm{N}^{\mathrm{n}} 1$ & Cop dho & 40 & - & 5 & - & 10 & & & & \\
\hline Oliuieri & $N^{0} 1$ & Cop dho & 40 & - & 5 & - & 10 & & & & \\
\hline Marini & $\mathrm{N}^{*} 1$ & Cop dho & 40 & - & 5 & - & 10 & & & & \\
\hline Falconieri & $\mathrm{N}^{n} 1$ & Cop tho & 40 & - & 5 & - & 10 & & & & \\
\hline Corradini & $\mathrm{N}^{0} 1$ & Cop dho & 40 & - & 5 & - & 10 & & & & \\
\hline Coscia & $\mathrm{N}^{0} 1$ & Cup dho & 40 & - & 5 & - & 10 & & & & \\
\hline Sante Ynes & $\mathrm{N}^{n} 1$ & Cop dho & 40 & - & 5 & - & 10 & & & & \\
\hline Lercarl & $N^{0} 1$ & $\operatorname{Cop}$ atho & 40 & - & 5 & - & 10 & & & & \\
\hline Bentiuoglio & $\mathrm{N}^{\mathrm{u}} 1$ & Cop dhe & 40 & - & 5 & - & 10 & & & & \\
\hline Conti & $N^{0} 1$ & Cop dho & 40 & - & 5 & - & 10 & & & & \\
\hline $\begin{array}{l}\text { Pnpe } M^{n} \\
\text { Milieto }\end{array}$ & $\mathrm{N}^{0} 1$ & Cap dho & 40 & - & 5 & - & 10 & & & & \\
\hline $\begin{array}{l}\text { Duq" de } \\
\text { Graulina }\end{array}$ & $N^{0} 1$ & Cop dho & 40 & - & 5 & - & 10 & & & & \\
\hline $\begin{array}{l}\text { Condest" } \\
\text { Colonna }\end{array}$ & $N^{0} 1$ & Cup dho & 40 & - & 5 & - & 10 & & & & \\
\hline Monsr Orsinl & $\mathrm{N}^{0} 1$ & Cop dho & 40 & - & 5 & - & 10 & & & & \\
\hline Mro de Cam" & $\mathrm{N}^{4} 1$ & Cup dhio & 40 & - & 5 & - & 8 & & & & \\
\hline Meyordorno & $\mathrm{N}^{0} 1$ & Cop dho & 40 & - & 5 & - & 8 & & & & \\
\hline Mayella & $\mathrm{N}^{0} 1$ & Cap atho & 40 & - & 5 & - & 8 & & & & \\
\hline Auditor & $\mathrm{N}^{0} 1$ & Cop Conca & 40 & Comisa & 5 & Doradura & 8 & & & & \\
\hline Prom' de la fee & $\mathrm{N}^{\mathrm{n}} 1$ & Cup dho & 40 & - & 5 & - & 8 & & & & \\
\hline Sec ${ }^{0}$ de Ritos & $\mathrm{N}^{0} 1$ & Cop dho & 40 & - & 5 & - & 8 & & & & \\
\hline Gou" de Roma & $\mathrm{N}^{0} 1$ & Cop dho & 40 & - & 5 & - & 8 & & & & \\
\hline $\begin{array}{c}\text { Postuf́ de S. } \\
\text { Juan de la } \\
\text { Cruz }\end{array}$ & $N^{u} 1$ & Cup dho & 40 & - & 5 & - & 8 & & & & \\
\hline
\end{tabular}




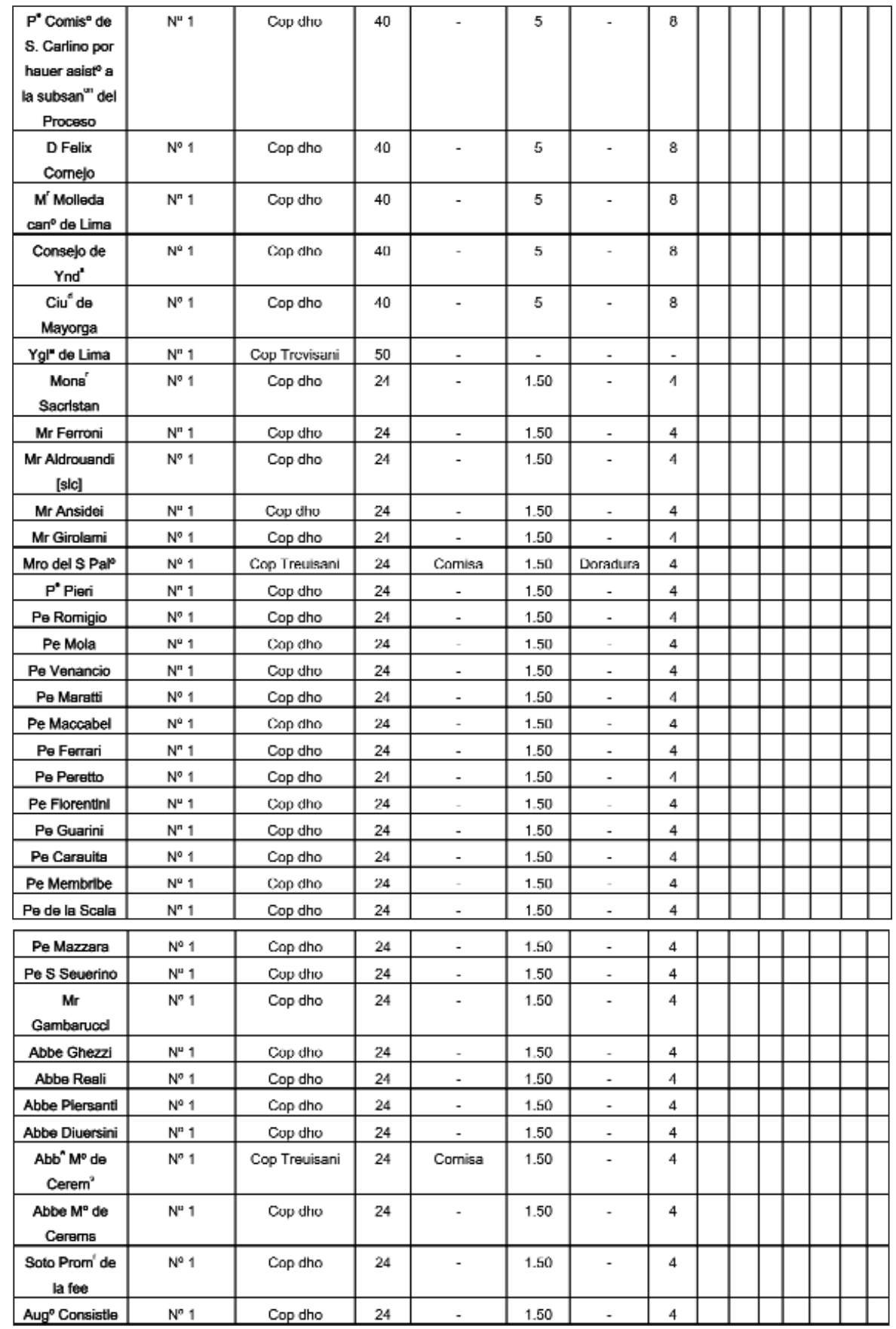




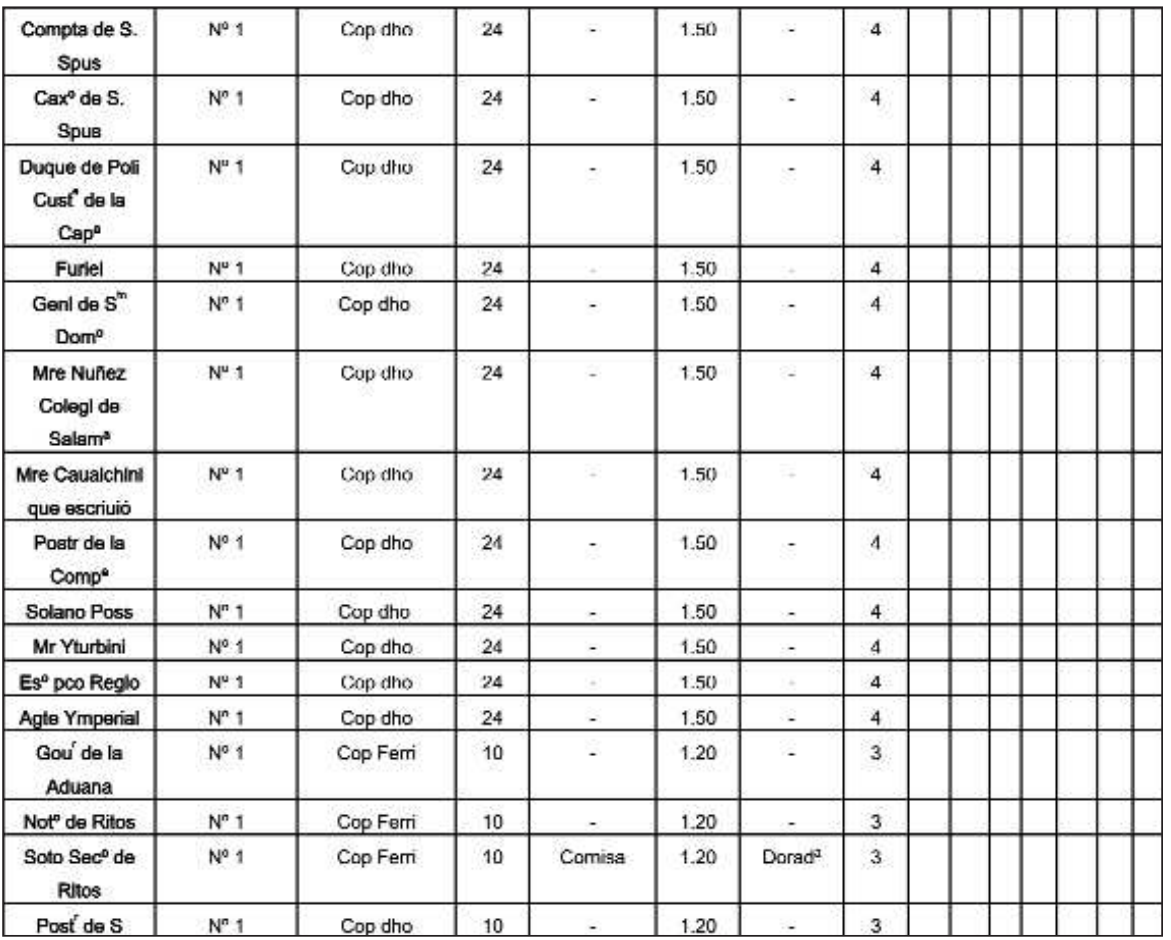

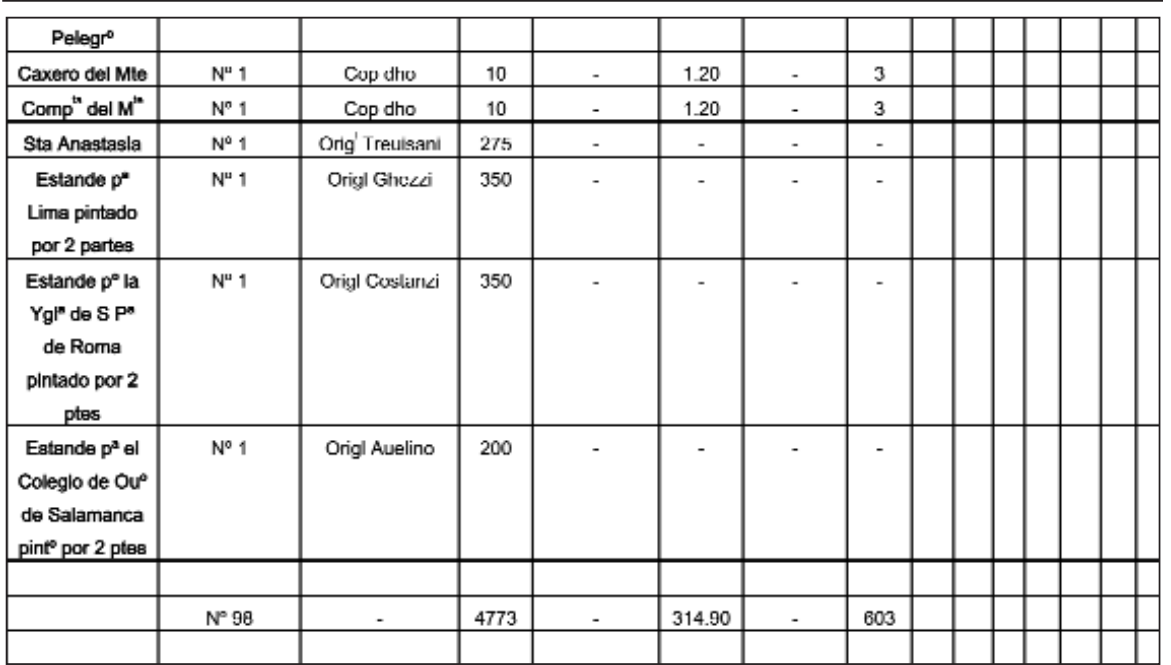


Restreto de los quadros

Los originales de Conca son uno de a escs 450 y otro de a escs 300: en num ${ }^{\circ} n^{\circ} 2$ 750

Los originales de Treuisani son num ${ }^{\circ}$

Los originales de Ghezzi son num ${ }^{\circ}$

Los originales de Constanzi son num ${ }^{\circ}$

n 1275

Los originales de Auelino son num ${ }^{\circ}$

$n^{\circ} 1350$

$n^{\circ} 1 \quad 350$

$\begin{array}{lll}n^{\circ} 1 & 00\end{array}$

Las copias de Treuisani a razon de a 24 escs $n^{\circ} 42$ y $n^{\circ} 2$ a razon de 50 escs $n \quad$ o $44 \quad 1108$

Las copias de Ferri a razon de 10 escs son

$n^{\circ} 6 \quad 60$

Las cornisas son

Todas $\quad n^{\circ} 98 \quad 4773$

Los 3 estandartes no tienen cornisas

$n^{\circ} 93 \quad 314.90$

El quadro de Santa Anastasia no tiene cornisa $\quad n^{\circ} 1$

El quadro de la Yglesia de Lima no tiene cornisa $\quad n^{\circ} 1$

En todo como Arriua

$\mathrm{n}^{\circ} 98$

Ya la doradura de dha 9ta y tres cornisas importa

$\mathrm{Y}$ en todo Ymporta el costo de dhos quadros cornisas y endoradura de ellos 5699.90

Restreto Genl del Ymporte

La pintura de los quadros $n^{\circ} 98$ en que se comprehenden los 3 estandartes, como se reconoce antecedentemte Ymporta

4773

Las cornisas según la referida nota importan

314.90

La Doradura como se apunta antecedentemte Ympta

612

Ymporta todo

3699.90

De los quales se han pagado a los Pintores como parece por la quenta Genl del Contador de la Causa es a saber.

En 30 de Marzo a Franco Treuisani con orden al Mte 100

En 1 de Abril a Placido Costanzi con orden ut sup ${ }^{a} \quad 100$

En 2 dho a Onofre Auelino con orden ut sup ${ }^{a} \quad 60$

En 3 dho a Sebastian Conca con orden ut sup ${ }^{a} \quad 100$

En 28 de Mayo al Cauallero Ghezzi con orden ut sup ${ }^{a} \quad 100$

En 22 de Junio a Franco Treuisani con orden ut sup ${ }^{a}$

$\begin{array}{ll}\text { Dho dia al dho Treuisani orden ut sup } & \\ & \end{array}$

En 6 de Julio a Onofre Auelino con orden ut sup ${ }^{a} \quad 40$

En 20 dho a Placido Costanzi con orden ut sup ${ }^{a} \quad 50$

Dho dia a Sebastian Conca con orden ut sup ${ }^{a} \quad 200$

En 6 de Sette a Franco Treuisani con orden ut sup ${ }^{a} \quad 206$

En 9 dhco a Sebastian Conca con orden ut sup ${ }^{a} \quad 300$

En 11 de Noue a Franco Treuisani con orden ut sup ${ }^{a} \quad 300$

En 11 de Noue a Placido Costanzi con orden al Mte 200

En 12 dho a Sebastian Conca con orden ut sup ${ }^{\text {a }} 400$

En 18 dho al Caur Ghezzi con orden ut sup ${ }^{a} \quad 250$ 
En 14 de Dicre a Franco treuisani con orden ut sup ${ }^{a}$

Y por el Descargo del sor D Felix por el $\operatorname{Din}^{\circ}$ que ha parado en su poder se han pagado es a saber

$\begin{array}{ll}\text { A Sebastian Conca } & 100 \\ \text { A Onofre Auelino } & 100 \\ \text { A Nicolas Ferri } & 40 \\ & 240\end{array}$

Al Carpintero por las Cornisas según parece por las qtas Gens del Contr de la Causa en 16 de Mayo de 1726 a Lorenzo Curty con orden al Mte de Piedad 50

Y por el Descargo del sor D Felix por lo que ha parado en su poder pags al mismo Curtis $293 / 343$

A los endoradores por lo que parece por las quentas Gens del Contr de la Causa con ordn al Monte de Piedad a Simon Gidone por finiquito 30

Y por el Descargo del sor D. Felix por lo que ha parado en su poder al mismo Simon Gidonien tres partidas 114

A Antonio Maggi 421

$\mathrm{Y}$ en todo 4588

De manera que se quedan deuiendo a los Pintores y demas comprehendidos en esta nota saluo error" $1111.90^{32}$

\section{7-IX-24. Roma}

El cardenal Bentivoglio al sr d. Francisco Díaz Roman

"Señor mio teniendo entendido q dn Felix Cornejo intenta anular una de las partidas, q ha puesto el Procr D Domingo Maria Vacari en el papel q me ha presentado de su credito contra la causa de sto toribio Mogrovejo, que despues de examinado, y tassado por el sr Cardl Belluga embie a VS y es la del quadro del Sto, la qual se le debe como Procr que ha sido de la causa de la canonizazion, sobre el pretexto de haverle ya dado el referido quadro, //vto lo qual quiere Dn Felix probar de un orden suyo de 40 exos para el Monte de piedad a favor del expresado Bacari por el equivalente del quadro, he creído de mi obligación prevenir a VS que el quadro que Dn Felix dice haver dado al Bacari, ha sido el q se le debia al principio de la causa, como VS podrá reconocer de la adjunta copia de orden, q Dn Felix trahe a su favor, y lo remito a VS para desengaño de la equivocacion de Cornejo, siendo costumbre, y estilo q entonces se dé uno al Procr de ella y otro despues de concluida, y decretada //sig la sanctificacion, que es el que presentemente pretende, y se le debe a Bacari: todo lo qual pongo en noticia de VS para q se sirva passarlo a la superior comprehension de los sres del consejo, a fin q esten iluminados de quanto ocurre en este particular. Ge Dos a VS ms as como desseo. Roma, 24 de sptre de 1727 "33.

\footnotetext{
30 Todo en 288 escudos, siendo pagados a cuenta 205. Idem.

31 Patronato, 249, R.17 (1)
} 


\section{7-IX-10.}

Copia de carta escrita a don Francisco Díaz Román, en 10-IX-1727 por el cardl Bentivoglio con despacho de 11 de mayor remitiendo la cuenta que don Gregorio de Molleda, obispo de Isauria envió a este consejo real tocande a los gastos de canonización. "El ultimo examen q queda pr hacer es por el gasto de los quadros, estandartes, cornisas, doradura //hoja 3 de las mismas, vanderado, y otros ocurridos por causa de los mismos quadros, y no puedo dejar de admirarme q el quadro para S. M. q debia embiarse ante todas cosas, y preferirse a qualqr otro se haya dejado para el ultimo, pues haviendose comenzado despues de todos, no está todavía acavado, y aunq esta omision puede atribuirse a puro descuydo, sin embargo, es digno de toda observacion.

Toda la suma de quadros, estandartes, y lo demas para dho efecto, importa 6086 exdos y 40 bs, los quales se han distribuido en la forma q se prescrive al folio señalado con la letra $D$. Y hablando en primer lugar de la suma, esta es excesiva en todas sus partes, respecto de q no se hallará causa de canonizazion hecha asta ahora, q haya consumido tanto dinero para tal efecto. Por los otros siete sto canonizados con sto Toribio se han gastado por cada uno menos de 2. Exos con q no se // comprende como por el solo sto Toribio se a triplicado el dispendio. El dinero juntado $p^{a}$ esta causa fue recogido de limosnas de fieles, y destinado para la gloria del sto la qual en nada se ha augmentado con gastarse de su Patrimonio una summa tan considerable. [...]

Ademas la distribucion de los quadros se ha hecho con sobrada libertad, pues a todos aquellos señalados con la * estrellita en la quenta, no se debia quadro alguno, no haviendo ni fatigado por la causa, ni dado ayuda para el feliz éxito de la misma..."34

\section{8-IV-9.}

Fiscal ha visto cartas de Bentivoglio que cuenta lo ocurrido con el obispo de Isauria. Se hace relación de la dependencia desde su origen "que se reduze a que estando de virrey del Peru el Duque de //vto la Palatta recogio de limosna 40. Ps para la canonizazon del sto cuia summa de orden del consejo se puso en poder de dn Alonso de los Rios canónigo de Lima q se hallaua en Roma para acudir a esta causa de orden de su cauildo que los puso a rredittos y despues se entregaron de orden tambien del consejo a Don Alonso Torralba Ajente de S. M. en aquella corte para que los administrase y multiplicase; $Y$ que estando en este estado la cassa de Silva que se hallaua declarada acreedora de vna gruesa summa de dinero contra el cauildo de Lima mediante tres sentencias conformes de la rotta en fuerza de las quales se auian expedido los mandattos cuio creditto probenia de auer dado el cau ${ }^{\circ}$ Silua 22.300 excos a cambio maritimo a vn cierto canonigo llamado Valladolid, que se hallava de procurador del referido cauildo de Lima para los gastos que ocurriesen de la Beatificacion de sto Toribio: Y que con este fundamento la cassa de Silua auia echo secuestrar los referidos capitales que el Duque de al Palatta auia recogido de limosna, pero que hauiendose despues controbertido esta materia en signatura, fue

\footnotetext{
32 Patronato, 249, R.17 (1)
} 
reuocado el secuestro... [puesto] que los capitales recogidos por el Duque de la Palatta no eran efectos del cauildo sino limosna de los fieles..."35

1734.

"Emmo y rvmo sr.

En la solemne santificac ${ }^{\text {on }}$ de santo Toriuio se dio incumbencia por Dn feliz Cornejo postulador de la causa de dicho santo al Cauallero sebastian Conca, Pintor de haçer todos los quadros neçesarios para la referida santificacon, los quales deuian seruir para la feliz memoria de Benedicto XIII para su Md Catholica, para los Señores Cardenales, para los Señores Prelados, Diputados y Consultores, de la Sagrada Congregaçon de Rittos, como con todo estudio, y diligençia se hizieron y distriuuieron y de ellos fue pagado el dho Cauallero Conca según el precio acordado.

Por la misma santificacon se comvino entre //vto el señor Dn feliz Cornejo, y Cauallero Conca de haçer por el preçio de 200 duos la lamina de dicho santo dedicado a su Md Catholica como tambien haviendo salido los quadros de maior grandezza de la que se hauia concordado, y querido el dicho señor Dn feliz, que los que deuian darse a los señores Cardenales, que fueron mas de 40 fuessen retocados de propria mano de dicho Conca prometiendole por ello un reconoçimto de 150 escudos, y ademas otros 50 escudos para los offiçiales del mismo Conca, que havian travajado, y otros 6 escudos y 50 baioqs al que pinto los regcados? alrededor de los quadros, y por otros gastos menudos echos por el trasporte de los espresados quadros // sig. cuias partidas importan en todo: 406 escudos y 50 baioqs según la inclusa quenta.

De toda esta suma de 406 escudos y 50 baioqs no a sido todauia pagado el dicho señor Conca por las diferencias naçidas entre los ministros, y por la partençia de Roma de dho Señor Dn feliz sin emvargo de hauerse imviado a españa la misma quenta y hauer sido approvada del señor Presiente del Consejo de Indias, y a no hauer suçedido su muerte a estas horas se huviera logrado la satisfacçion, tanto mas que el dinero esta ya depositado en los bancos de Roma, no solo para este effecto sino tambien para pagar otras personas que traua // vto jaron en dicha santificacon. En este estado de cosas el expresado Cauallero conca recurre a v em ${ }^{a}$ para que se digne escriuir al Nueuo Señor Presidente del consejo de Indias, por la expediçion de las ordenes opportunas, para el dicho pagamto a fin que se pueda presentar a Su Md Catholica al expresada lamina, que todauia se halla en poder del mismo Cauallero Conca, y difundir por todas las partes del Mundo, y particularmte en las Indias, la figura, y la ymagen de santo Toribio, a cuio fin se ordeno y se hizo //img 9 Al emmo y Bmo sor Cardenal Belluga Ministro de S M catca.

Por

El Pintor Cauallero Conca."

"Ha de hauer el Cauallero Sebastian Conca, Pintor, pr la lamina de santo toribio, dedicada a S. M. C.... 200

33 Patronato, 249, R. 17 (2). 
Mas pr reconocimto pr hauer retocado de su mano mas de 40 Quadros... 150

Mas a los oficiales del mismo Conca de reconocimiento... 050

Al que pintó los regulos alrededor de los quadros, y otros gastos... 006.50 $406.50^{36}$

1734-I-3.

"Excmo sr.

Señor mio el em ${ }^{\circ}$ Acquauiua me ha embiado con su Auditor el meml adjunto con la Lamina y estampa q remito por el Correo pidiendome yo suplique a $\mathrm{V} \mathrm{Ex}^{\mathrm{a}}$ se sirua dar prouidencia para q de los caudales existentes en este Monte pio pertenecientes a la Canonizazion de Sto toribio se le de satisfaccion y estando en essa Corte como creo Dn Felix Cornejo, mandandole V Exa le informe de su contenido, si fuere assi lo $q$ el meml expresa no dudo dara $V E^{a}$ prouidencia a su satisfaccion. Yo no se qn corre oy con estos caudales, ni a qn este encargado lo q anualmte rinden los Lugares de Monte, rembestirlo por q no he tenido incumbencia ninguna en esto;

Y la adjunta peticion debo anadir q abra me parece dos años q yo escriui al Secretario del RI Consejo de las Indias para q representase el Consejo auer recurrido a mi el impresor Rosi, diciendome auia estampado la vida de Sto toribio q de orden de Monsr Obpo de no se //vto se q obispado de las Indias, q corria con la dependencia de la Canonizazon q tenia en su casa Dn Felix Cornejo como pariente de su Muger auia compuesto el Pe Laderchi de la Congon del Oratorio el q dedico a dho RI Consejo embiando una copia, y q no se le auia pagado dha Ympresion ordenada pr dho Pe Laderchi, y quasi aprobada por mi por ser una vida bellissimamte escrita, la q dho Pe despues de hauerla yo visto, y parecidome excelentemte quiso se estampase con la seguridad de q dho RI Consejo mandari [sic] se pagase de dhco caudal la ympresion, o se ayudase a ella, viendola y reconociendola, y el agrauio $q$ el dho $\mathrm{Pe}$ se le auia hecho en ordenarle no la prosiguiese, guardala tenia ya quasi finalizada, por lo q a representacion mia se le libraron a dho pe por el Consejo no se si sesenta o 80 escudos q su trabajo y el de su Amanuense y diciendole al referido secretario me parecia justo, y debido q a este pobre Ympresor se le diese alguna satisfaccion por dha Ympression, y sesenta escudos q se le librasen me parecia vastante ayuda, me respondio hauia dado parte al RI Consejo, y que le parecia muy justo y daria parte a Su Magd como $\mathrm{V} E \mathrm{x}^{\mathrm{a}}$ lo reconocera por la adjunta.

Despues murio dho secretario, y no se ha vuelto a // a hablar de esto, y yo por commiseracion le di 20 escudos para reintegrarme de ellos qdo se le librasen los sesenta Estimaré a V Ex ${ }^{a}$ mande se busque la carta q yo escriui y Decreto del RI Consejo y q a este pobre se le de la referida ayuda. Todas estas dependencias quedaron indigestas con las dispuestas q se ofrecieron entre el $\mathrm{Em}^{\circ}$ Bentibollo difunto y Dn Felix Cornejo, sobre qn auia de entender en estos caudales, y como Dn Felix se fue nunca supe el termino q auia tomado esta materia como cosa q no me importaua quedo a la obed ${ }^{a}$ de $V E x^{a}$, y ruego a Nro sr le gde mos aos. Roma y Henero 3 de 1734" Cardenal Belluga a don Josep Patiño37. 
1734-I-30.

"Paso a manos de VS de orn del Rey la adjunta carta del Cardl Belluga con la q yncluye origl de dn franco diaz Roman y meml del Pintor q abrio la Lamina de la estampa de sto Thorivio Mogrouejo, para q hazien- //vto Vs presente en el Consejo de Yndias, se dé por este la providencia de q se satisfaga al expresado Pintor lo que se le esta deviendo, y a otros acrehedores de los caudales que existen procedidos de la canonizazon..." El Pardo, 30-I-1734. Sor d. Miguel de Villanueva por Joseph... 38

1734-III-13.

"El Rey.

Mui Rdo en xpto Padre Cardenal Belluga, mi mui charo y amado Amigo, por Real Cedula de $1^{\circ}$ de Marzo del año de 1729 se previno a el Cardenal Bentivoglio que de los caudales que havia existentes en los depositos y lugares de Monte, y se havian recogido de Limosnas, y estavan destinados para los gastos de la Canonizacion de Sant Thoribio Morgobejo [sic], dispusiese se sacasen y entregasen mil ochocientos ochenta y cinco excudos a dipsosicion del Padre fr. Joseph de la Madre de Dios, religioso del orden de trenitarios Descalzos, y Prior del Combento de san Carlino, poder // haviente de Dn Feliz Cornejo, $\mathrm{p}^{\mathrm{a}}$ que con ellos pudiese este Religioso pagar las deudas que se avian contrahido, en la Canonizacion del referido sto thoribio... //sig $\mathrm{Y}$ ahviendo puesto en ejecucion la expresada RI orden participo el mencionado Religioso aver pagado a los acrehedores 1.824 exos y 36 vayoques, y que los sesenta y un exos restantes cumplimto a los dhos 1.885 que se decian ser para los gastos de Medalla, cajones, y otras cosas, los havia dejado en el mismo Vanco y Monte por no ser suficiente esta corte porcion para su compra, y remesa... // ... deven añadirse otras dos partidas, la vna de 600 exos romanos que parece haverse arreglado deuerse dar para diferentes recompensas hechas en veneficio de esta causa, y otra de 369 exos y 37 vaiocos que se pueden considerar para los gastos de la conducion y fletes hasta Cadiz de los quadros y demas adornos que estan en esta Corte, y deuen conducirse a esta, para mi RI persona y Consejo expresado, y para las Medallas que deven remitirse a la dha Yglesia de Lima, que todo importa 2. exos romanos, cuia cantidad es preciso se satisfaga y pague del referido caudal, de Lugares de Monte... //... separandose de ella 3.200 exos romanos que por dha Yglesia se ha convenido entregar al citado mi Consejo, y es la que por el de ha regulado suficiente para que vna efige [sic] q del santo se hizo quando en esta Corte se celebraron las fiestas de su Canonizacion, se coloque en la Yglesia del Combento de Nra sra del Carmen, con vn Retablo v adorno en que tenga el devoto decente Culto que corresponde... " El Pardo, 13-III-1734. El Rey. Por su mandado don Miguel de Villanueva 39 .

\section{4-VI-27. Madrid}

"Señor mío. Paso a manos de VS. El Papel adjunto del Prior del comvento de Nra sra del Carmen Calzado de esta Corte, con la declaracion que incluye del Maestro de

\footnotetext{
36 Patronato, 249, r 22 (1)

37 Patronato, 249, r. 22 (1)
} 
obras, sobre el considerable y prompto reparo que necesita la Capilla Mayor, para precaver el riesgo y ruina que amenaza con la proposicion que al mismo //vto tiempo hace, de colocar en la nueva capilla de Nra sra que intenta fabricar, la efigie del Glorioso sto Toribio con su adorno y Altar correspondiente, precediendo la licencia del Consejo y beneplacito del Patrono; para que dando quenta en el de su contenido, y en que no encuentro el mas leve reparo, ni perjuicio hacia la autoridad del Consejo y regalia del Patronato, se digne su // grandeza, resolver, lo que tubiere por mas conveniente, y VS. de participarmelo, a fin de que pueda yo, satisfacer a este Religioso, con muchas ordenes de su mayor agrado.

Dios ge a VS mos aos como deseo. Madrid 27 de Junio de 1734.

BIm de VS su mas segdo seror.

El Marqs de Belzunce (rub).

Sor Dn Migl de Villanueva"40.

1734-Vl-27.

"Señor mio. Paso a manos del VS el papel adjunto del Prior del comvento de Nra sra del Carmen Calzado de esta Corte con la declaracion que incluye del Maestro de obras sobre el considerable, y prompto reparo que necesita la Capilla Mayor, para precaver el riesgo y ruina que amenaza, con la proposicion que al mismo // vto tiempo hace, de colocar en la nueva capilla de Nra sra, que intenta fabricar, la efigie del Glorioso sto Toribio con su adorno y Altar correspondiente, precediendo la licencia del Consejo y beneplacito del Patrono; para que dando quenta en el de su contenido, y en que no encuentro el mas leve reparo, ni perjuicio acia la autoridad del Consejo, y regalia del Patronato, se digne su // grandeza, resolver, lo que tubiere por mas conveniente, y Vs de participarmelo, a fin de que pueda yo, satisfacer a este Religioso, con muchas ordenes de su mayor agrado.

Dios ge a Vs mos aos como deseo. Madrid 27 de Junio de 1734.

BIm de VS su mas segro seror. El Marqs de Belzunce."

A Dn Migl de Villanueva.

Visita de Vicente Alonso Torralba, arquitecto y maestro mayor de obras de la ciudad de Toledo y maestro de obras en la Corte

"Digo yo d Vicente Alonso Torralba, Arquitecto y Mtro Mayor de obras de la Ciud de Toledo Residente en esta Villa de Madrid, y tambien Mtro de obras en ella, que de horden del Rmo P Mtro fr Joseph Ortiz delgado, Prior en su Combto del Carmen Calzado, he visto y reconocido la Capilla Mayor de dho combento, y en ella he hallado necesita de diferentes reparos Mayores y menores en las partes sigtes.

Primera mente he reconocido en el testero del cruzero (lado de la Epistola) es manifiesto una quiebra q principia desde la cornisa exterior q sirve de reciuir el Alero del texado y atrabiesa por el Arco Dintelado de la ventana y baja su operación atrabesando por el medio de el Lienzo, dividiendose en dos ramos, uno q es maior que mira a el Altar Maior, y el otro a el cuerpo de la Yglesia, manifestandose por la parte ynterior mui abierta y por la exterior con mas operación y perjuicio, comunicandose asta el Arco de la Puerta (que hai en dho testero) todo el lienzo de la Pared cuarteado.

38 Patronato, 249, r. 22 (1) 
Tambien se reconoze el cañon de Boveda q perteneze a el crucero lateral (q se une con el dho testero de la quiebra) se halla sentido, y no menos q llega hasta el Arco toral y aun el mismo Arco toral y Anillo se allan sentidos o abiertos, y todo manifiesta la flaqueza del cimiento pues ocasiona desunir aun lo que no es fabricado con el Lienzo de la Pared testero.

Y declaro q fabricandose (como se fabrican) los cañones de Boveda de Ladrillo de canta y Doblado (q llaman chapado) si este jenero de obra llega a desunirse el un medio caño del otro, podra suceder caerse a la Yglesia haciendo mucho daño" 41.

1738-VI-11. Madrid.

"Se podria dar Orden para que el sr Cardenal Belluga, hiciese que se desvinculasen de dichos Lugares los mencionados 8.911 escudos y sus redictos, y de ellos se satisfaciesen 2.- escudos a fr. Joseph de la Madre de Dios para que pagase las deudas que a credito de dn Felix Cornejo se havian contrahido en esta causa, y tambien para los costos de dos Quadros del santo, que se havia de remitir para el Rey, y el Consejo, y las Medallas que se devian embiar a la Yglesia de Lima.

Que se remitiesen al Consejo, tres mil y docientos excudos Romanos, que havia comvenido la referida Yglesia de Lima se le entregasen, y se havian regulado suficientes para una efigie del santo // que se hizo quando en esta Corte de celebraron las fiestas de su canonicacion se colocase en la Yglesia del Carmen con un Retablo o adorno en que tubiese el devoto decente culto que corresponde. Y que los 3784 excudos y 60 vayocos, que restavan de este caudal, y lo que hubiesen importado sus intereses, se entregasen al Apoderado de la Yglesia de Lima, para con ellos transigir en el mejor modo la deuda de la Casa de Silva. Y aviendose conformado S. M. en todo con este dictamen del Consejo, se expidieron las cedulas correspondientes al sr Cardenal Belluga a fray Joseph de la Madre de Dios, y a dn Joseph Garcia del Pino, Apoderado en Roma de la dha Yglesia de Lima: Los quales respondieron ensartas de los años de 1734 y 735, remitiendo al Consejo 4. pesos de a ocho reales de plata, que importavan // los citados 3200 excudos Romanos, dando quenta de que se havian dirigido por Genovaa esta Corte, los Quadros para S. M. y el Consejo, y 30. Medallas de Santo Thorivio y santa Rosa a Cadiz, para embiar a Lima, y pagado los fletes de todo: $Y$ que se hallava ya satisfecha la casa de Silva de la deuda que suponia tener, y sobraban 1.971 excudos Romanos y 57 vayocos para la Yglesia de Lima.

Con este motivo, y haverse escrito un papel por el Prior del Carmen al $\mathrm{Sr}$ Decano del Consejo, incluiendole una declarazion del Maestro de Obras, tocante al prompto reparo que necesitaba la Capilla maior de su Yglesia: Proponiendo dicho Prior que para colocar en la nueva Capilla de Nra Señora que se intentava fabricar desde la Puerta del Colateral, que sale al Atrio // y gradas de san Juan, hasta la linea de la Casa donde el Consejo tiene su tribuna la efigie de santo Thorivio con su adorno y Altar correspondiente en el Crucero de la misma Capilla al lado del evangelio, tomandose para esta nueva Obra como tres pies de la referida casa, sin llegar a tocar, ni impedir el paso a la tribuna concluiendo en que dejando esta con sus dos

39 Patronato, 249. R 22 (2) 
Aposentos para el Sr Patrono y entrada por la Calle y escalera, commas decendia de la que al presente tiene, se diese al Comvento lo demas restante de la Casa para usar de ella a su voluntad trajo el Sr Decano al Consejo, el citado papel;...

$Y$ despues con Papel de $1^{\circ}$ de Junio de 735 , se remitio a los mismos dos señores Decano, y dn Fernando Verdes, la letra que vino de Roma de 60. Rs de vellon para la citada obra del Carmen;"

"...y respecto de no poder tener efecto la primer Ydea, no ha parecido, según el tanteo hecho, que lo que podrá executarse con los 3200 escudos existentes, comunicado con el Prior y Religiosos de la Orden, es un tabernaculo con su Graderia, que le acompañe por los lados, revajando una Grada del Presbiterio, y colocando la Ymagen del sto entre el tabernaculo y la de la Virgen ssma, y en el casso de no caber en este sitio la efigie, ponerla entre su Magd y la ssma trinidad, lo que parece se podrá costear hasta la ultima perfeccion con 32 a 34. Rs, obligandose con el resto la comunidad a celebrar perpetuamente una fiesta annual del sto en su proprrio dia con Missa solemne, sermon, y exposicion del Ssmo Sacramento, sin que jamas puedan ser menos de 60 las velas, que adornen el Altar, y que si en el dicho dia huviesse algun embarazo..."

Madrid, 11 de junio de 1738. fdo Marqs de Belzunce; Fdo Verdes Montero42.

\section{0-III-8. Madrid}

A don Miguel de Villanueva, por Francisco Ruiz.

"Muy sr mio; en cumplimiento de la Orden del Consejo, participada por VS pasamos dn Pedro de Riuera, y yo ayer Lunes al reconocimiento de la Capilla maior de la Yglesia del Carmen, el que hicimos con asistencia del Pe Prior, y en su consequencia hemos formado la adjunta declarazon //vto que remito a Vs juntamte con la que se siruio embiarme hecha en el año de 1733 por Dn Vicente Alonso Torralba. Y tengo por combeniente que de las dos? Obras propuestas en la nuestra (eligiendo el Consejo, la que fueze de su agrado), se ejecute en este año para obiar sustos, y maiores gastos el que viene pero esta Santa Quarentena se puede sin cuidado asistir a los sermones que en esta Yglesia tiene el Consejo. // Dios Gue a Vs con salud felizes años que he menester. Madrid, Marzo 8 de 1740.

Perdone Vs no escriuir de mi mano porque la vista me aiuda poco.

BLM de Vs su mas rendo y afectto seruor. 